\title{
Energy Efficient Process Planning System - The ENEPLAN Project
}

\author{
Paolo Calefati ${ }^{1}$, John Pandremenos ${ }^{2}$, Apostolos Fysikopoulos ${ }^{2}$, \\ and George Chryssolouris ${ }^{2, *}$ \\ ${ }^{1}$ PRIMA INDUSTRIE S.p.A., Via Antonelli 32, 10097 Collegno (TO), Italy \\ paolo.calefati@primapower.com \\ ${ }^{2}$ Laboratory for Manufacturing Systems and Automation, \\ University of Patras, Rio, Patras 26500, Greece \\ \{jpandrem, afysiko, xrisol\} @lms.mech.upatras.gr
}

\begin{abstract}
The key factor to success, towards a competitive energy consumption reduction, is the effective involvement of SMEs both in the use of more efficient machines and in the Design of an Environment for new products. A specific product can be manufactured in different ways, based on cost optimization rather than on production flexibility and energy efficiency with the involvement of different suppliers. The ENEPLAN project aims at the development of a digital and real, energy-efficient, multi-process, networked, manufacturing system, adapted to the functional specifications of metal formed or machined parts for automotive, aeronautic and domestic appliances. Seventeen partners, coming from seven European countries and the participation of OEMs, SMEs, RTD and technology providers, who work jointly to deliver through ENEPLAN a manufacturing planning decision support tool (meta-CAM tool), for the optimization of the plant operation. This tool will be used from the conceptual phase of the product (final blueprints) to its final dispatch to the customer. This paper will provide a short overview of the ENEPLAN project and its ongoing developments, while the existing results will be presented and discussed and the next steps will be described.
\end{abstract}

Keywords: Energy efficiency, process planning, Meta-CAM tool, process optimization.

\section{Introduction}

Today's manufacturing plants provide a number of different processing possibilities for the manufacturing of a specific product. Each one of these processing possibilities poses different advantages and limitations that are functions of both the geometry and the lot size of the part to be manufactured. However, one of the main driving forces in today's production, as shown below, is the environmental friendliness and the energy efficiency of the production itself. Additionally, the manufacturing processes are required for quickly enabling the shifting between diverse manufacturing operations with short transfer, program and set-up times without compromises to quality, reliability and life-cycle costs.

\footnotetext{
* Corresponding author.
} 
The machine tools sector is one of the most relevant in Europe in terms of GDP (180 billion $€$ of new orders before the crisis, 74 billion $€ / y$ in Q2 2010) [1], the sector mainly comprises SMEs (among machine users: $99.7 \%$ by number, $78.2 \%$ by GDP, 82.8 by persons employed among machine manufacturers: $98.7 \%$ by number, 49.7 by GDP, 56.5 by persons employed) [2]. In the same way the relevance of the sector in terms of energy consumption is high ( $>10,000 \mathrm{PJ} / \mathrm{y})$ [3] and consequently, the financial pressure is high due to the unbalanced demand/offer of energy, which results in increasing the energy price (as in 2007-2008). Additionally, the recent developments in manufacturing production technologies brought about machines and processes of higher performance and higher energy utilization, in order for the productivity and reliability of the process to be increased. Besides, the growing environmental awareness of people worldwide has led to legislative pressure (EuP Directive) [4] and it is highly probable that tool machines will be subjected to energy efficiency regulations and classification in the years to come [5]. The potential of energy savings in the machine tool sector is high (e.g. low power factor of 0.7-0.8), as the potential efficiency increases by exploiting the Design for Environment strategies (e.g. reduction of mass, materials used, extension of tool lifetime, optimised PWB, CPU, monitor) [3]. Recent studies have shown that there is heavy unnecessary energy use in the industrial sector; typical figures for machining equipment are in the range of $20 \%-50 \%$.

Today's European market has to deal, more than ever before, with highly demanding customers. In order for these advanced needs to be addressed, a large number of alternative products are being produced from the same production line within the industry. Additionally, the products are characterized by a short lifecycle since they are quickly depreciated. Thus, flexible manufacturing processes should enable the immediate shifting between diverse manufacturing operations with short transfer, program and set-up times as required, without compromises to quality, reliability and life-cycle costs.

Today's process planning [6] approach is based on expert systems that are able to propose alternative process plans for the manufacturing of a specific product. Additionally, there are tools that can simulate the operation of each machine station both from technological (process parameters, energy efficiency, etc) and economical point of view. All of the systems available though, can cover only portion of the production, requiring the exchange of data between different systems and thus, making the overall optimization of the plant operation a hard task.

ENEPLAN Project [7], as an NMP (Nanotechnology and nanosciences, knowledge-based multifunctional materials and new production processes and devices), is the Third Thematic Priority of the Focusing and Integrating research part of the Sixth Framework Programme aiming at Industrial research - which remains a key objective of FP6 in an evolutionary world. ENEPLAN is co-ordinated by the PRIMA INDUSTRIE Group and is initiated and managed by the Laboratory for Manufacturing Systems and Automation of the University of Patras. This project aims at delivering a manufacturing planning decision support tool for the optimization of the plant operation that will be able to be used from the conceptual phase of the product up to its final dispatch to the customer. The ENEPLAN consortium consists of 17 partners: 
- two top-level OEMs from two different industrial sectors (CRF and GORENJE)

- one aeronautics sector supplier (NEW)

- four metal forming machine builders (PRIMA, FINNPOWER, GIZELIS and GIGANT)

- three users of those machines and suppliers of metal formed components to the above mentioned OEMS (TEKS, IAM and EXALCO)

- four high-ranked European university Labs (LMS, VTT, ITIA-CNR and AMRC)

- three "knowledge intensive" companies as RTD providers (CADCAMATION, CASP and IDEKO).

\section{ENEPLAN's View Beyond the State of the Art}

ENEPLAN aims at minimizing the inactivity time and waste streams, parameters that cover more than $30 \%$ percent of the energy used by machine tools. By using LCA methods and taking into consideration the consumption of natural resources, the waste streams will be accurately estimated and their environmental impact is to become clear. Furthermore, reliable and flexible process monitoring and controlling systems, for both conventional and non-conventional production technologies, will be developed. Finally, the introduction of novel simulation systems will result in reducing the required pre-production setup experimentation effort and subsequently increase the energy efficiency of the processes and the relevant machine tools.

The problem of energy management is solved by Load Management Systems; when a peak occurs, usually the system reactively reduces the power, instead of suggesting a better production planning [8-10]. Within ENEPLAN, a set of developments such as the identification of product's unique signature (CAD model, engineering requirements etc.), the monitoring systems and the multi-objective simulation techniques, will be all embedded into a Meta-CAM tool in order to be utilized for the optimization of the production planning, in terms of energy efficiency and other defined aspects. The existing systems are not capable of addressing the simultaneous consideration of many parameters, during optimization.

Since simulation engineering has since long been believed to be an enabling technology for life-cycle decision support [11-13], ENEPLAN will introduce a breakthrough to the current problem of optimization and decision making with simulation. Novel multi-objective simulation techniques will be introduced, with integrated techno-economical parameters and the assessment of different automation options will be applied to the evaluation of the process plans and the optimization of the production planning. In order for the process plan to be accurately evaluated, special attention will be paid towards the precise estimation of demand and production requirements throughout the product's life cycle. By utilizing analytical and numerical models on macro and micro/nano-scales, new reliable, production oriented process models, based on process parameters and particular process conditions, will be developed. Furthermore, models, either analytical and computational, or empirical, will also be developed for the analytical description of conventional and non-conventional processes. 
Taking into consideration the state of the art [14-17], the proposed research work will aim at the development of a simple, nonetheless, an effective method that will guide the process engineer in constructing generic process plans adaptable to all possible different scenarios that market needs. Therefore, shortcomings might be revealed in the design of the product and alternative approaches will be assessed for the production of the product (such as use of alternative equipment, resources, or even subcontracting).

During the development of the meta-CAM tool modules, various optimization algorithms and methodologies will be evaluated and compared by their applicability and efficiency. In particular, heuristic methods, specific for energy efficiency optimization, will be used, in conjunction with Pareto-optimal based multi-objective optimization in order for the optimization efficiency to be enhanced. The meta-CAM tool, integrating the output of ENEPLAN RTD efforts, will offer multi-disciplinary and multi-level simulation, optimization and information modeling components. In addition, in order for the integration of them to be supported, a common/open source integration architecture will be used offering extensive compatibility with various production related software.

\section{The ENEPLAN Project}

The current industrial status indicates that the key factor to success, in a competitive energy consumption reduction, is the effective involvement of SMEs both in a more efficient use of more efficient machines and in the Design for Environment of new products. In the ENEPLAN project, the main objective is the development of manufacturing systems that will be highly flexible, and at the same time, are closely adapted to the single product. These manufacturing systems need an engineering tool that can cover the entire plant operation, from the overall planning of the plant operation (such as the routes that the product follow within the plant and the scheduling of the production) down to the individual process programming. Today's process planning approach is based on expert systems capable of proposing alternative process plans for the manufacturing of a specific product. Additionally, there are tools able to simulate the operation of each machine station technoeconomically. All of the systems available though, can cover only part of the production, requiring the exchange of data between different systems and thus, rendering the overall optimization of the plant operation a hard task. The ENEPLAN project will deliver a manufacturing planning decision support tool for the optimization of the plant operation to be used from the conceptual phase of the product up to its final dispatch to the customer.

\subsection{The Concept}

A specific product, based on the cost optimization rather than on production flexibility and energy efficiency, can be manufactured in different ways and by 


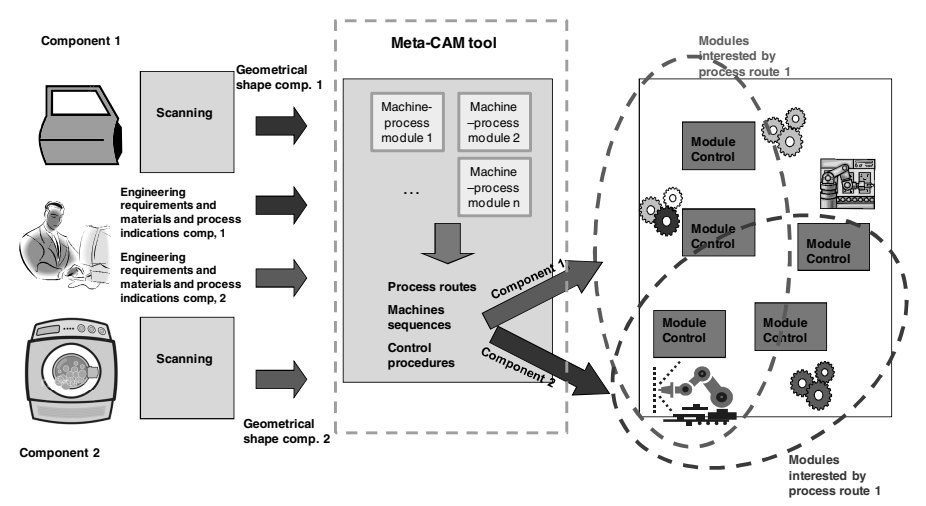

Fig. 1. ENEPLAN Concept

different suppliers. ENEPLAN aims at the development of a digital and real, energyefficient, multi-process, networked, manufacturing system adapted to the functional specifications of metal formed or machined parts for automotive, aeronautic and domestic appliances:

- digital and real: a new CAPP-CAM digital platform will be developed with a DSS that would allow choosing among alternative processing cycles, based on the best compromise between energy and cost efficiency.

- energy-efficient: a new optimization strategy will be implemented on the digital platform to minimize lifecycle energy consumption of the selected process. In this optimization materials, process technologies and machine cycles will be taken into account. Furthermore, all the end-users involved will evaluate the substitution of the existing machines with more efficient ones of the next generation.

- multi-process: on the digital platform, alternative processes will be considered for the same product emphasizing a breakthrough potential for energy reduction through the introduction of new technologies in the process (e.g. cutting and forming as alternative to machining).

- networked: optimization focus will be given to the manufacturing processes involving both multiple steps and companies along the supply chain, as well as SMEs. The involvement of SMEs is one of the pillars of ENEPLAN and, as a matter of fact, the SMEs partners in ENEPLAN account for more than $40 \%$ in number and $25 \%$ in budget.

The ENEPLAN's Meta CAM tool functions will perform the following:

- Process CAD data inserted either from a mathematical model or from shape acquisition of physical models through scanning

- Accept engineering requirements and material from a human operator

- On-line (or short-time) configuration of the manufacturing system

- Simulation of an overall manufacturing system, optimization and tuning for top production efficiency and minimum environmental impact

- Determine material selection, work sequences, cycles and process routes 


\subsection{The Main ENEPLAN Objectives and Targets}

The main objective of ENEPLAN is the development of the Meta-CAM tool for optimum process planning from a given set of production requirements.

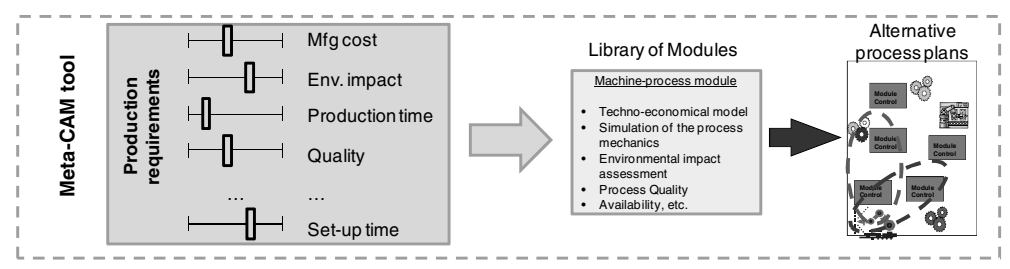

Fig. 2. The Meta-CAM tool

This system and its related technologies will enable the:

- Environmental footprint reduction for a metal formed component by selecting a more energy efficient combination of processes among those available in the already existing supply chain

- Target: $-40 \%$ of the lifecycle energy consumption (from cradle to grave), estimated $8 \mathrm{MJ}$ per component, 14.4 GJ per production life.

- Energy efficiency improvement in working conditions

- Target: estimated energy consumption -30\%, 2 MJ per component, 3.6 GJ per production life.

- Multi-process, multi-company distributed control

- Target: use of the same control along the supply chain, possibility to use the system that would adapt the work sequences, the process routes and machines' behavior to the most efficient working conditions.

\section{ENEPLAN Business Cases}

Besides these technical breakthroughs, additional "non-technical" ones will be triggered that will enable a vertical integration in the value chain and a horizontal integration by the ability to transfer the knowledge to other industrial sectors. ENEPLAN will promote breakthroughs on scientific and technical excellence, moving three at least industrial sectors (automotive, aeronautics and domestic appliances) and their involved partners in the vertical value chain, towards a multiobjective optimized production, by combining excellent research capacities of EU OEMs, SMEs, academic partners and technology providers.

The automotive business case will investigate a seat frame. The current automotive seat frame is manufactured by shaping different steel metal sheets or tubes. The MetaCAM tool will facilitate the evaluation of different technological scenarios and materials, most suitable for a targeted volume production by taking into account a weight and energy manufacturing process reduction. The results will provide an 


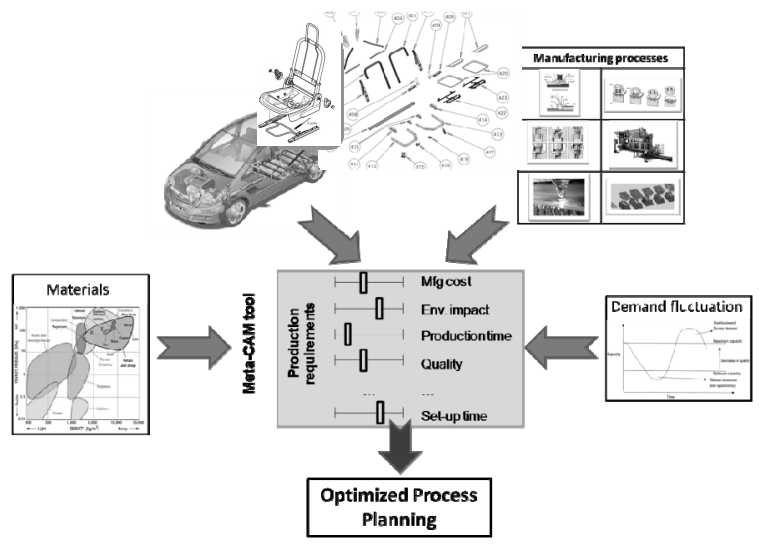

Fig. 3. Application of ENEPLAN's approach to the automotive pilot case

optimization of the final production cost and energy and raw material consumption within the target of a specific production rate at the same original product mechanical performance. Alternatives, in terms of forming technologies and the selection of different raw materials, will be evaluated. Optimization of the process by the elimination of steps, due to a reduction in the parts, may be integrated.

The Aeronautics Business case will use as pilot case the Lading Ramp Hinge of a military aircraft. The target with the use of the ENEPLAN's Meta-CAM tool is the energy consumption reduction and the factory's carbon footprint improvement. Moreover, establishing whether other processes are preferable to milling (main processes currently used), for the machining of the produced part and propose alternate process routes.

The household business will use as a pilot case six versions of the front panels of refrigerator doors. These parts contain high quality demands (Visible surfaces without aesthetics faults and all dimensions in tolerances). Currently, the existing process plan requires a lot of transportation between the different stations that increase the energy consumption. The LCA algorithms that will be included in the Meta-CAM tool will aid in finding alternatives and reducing the environmental footprint in the current factory.

\section{Conclusions}

The ENEPLAN project having as its primary objective to help the industry save energy, time and become more flexible, has come up with the development of the ENEPLAN Meta-CAM tool that has already set the specifications of the problem, selected and defined as well as the pilot cases that the Meta-CAM tool will run. The project now is in the phase of modeling and monitoring the business cases processes in order to provide input for the development of the tool. The finalization and validation of the tool is estimated to become true after the April of 2013. 
Acknowledgements. The work reported in this paper was supported by the collaborative program entitled "Energy Efficient Process planning System ENEPLAN" which in under the seventh framework program - FoF.NMP.2011-1: "The Eco-Factory: cleaner and more resource-efficient production in manufacturing Program".

\section{References}

1. CECIMO Statistical Toolbox, September 2010 Edition (2010), http: / /www. cecimo.eu

2. EUROSTAT 2012 (Key figures on European business) (2010) ISSN 1830-9720

3. Draft Working Plan of the Ecodesign Directive (2009-2011)

4. Directive of the European Parliament on Energy using Products (2005/32/EC)

5. Dietmair, A., Verl, A.: Energy consumption forecasting and optimization for tool machines. In: Institute for Control Engineering of Machine Tools and Manufacturing Units (ISW), Universität Stuttgart, http: / /www.mmscience. eu / archives / MM_Science_20090305.pdf

6. Papakostas, N., Efthymiou, K., Georgoulias, K., Chryssolouris, G.: On the configuration and planning of dynamic manufacturing networks. Logistics Research 5(3-4), 105-111 (2012)

7. ENEPLAN site, http: / / www . eneplan.eu/

8. Jebaraj, S., Iniyan, S.: A review of energy models. Renewable and Sustainable Energy Reviews 10, 281-311 (2006)

9. Bhatt, M.S.: Energy audit case studies I - steam systems. Applied Thermal Engineering 20, 285-296 (2000)

10. Trygg, L.: Swedish Industrial and Energy Supply Measures in a European System Perspective. PhD Thesis, Division of Energy Systems, Linköping University, Sweden (2006)

11. NSF Blue Ribbon Panel: Simulation Based Engineering Science, NSF Report (2006), http://www.nsf.gov/pubs/reports/sbes_final_report.pdf

12. Fu, M.C., Andradóttir, S., Carson, J.S., Glover, F., Harell, C.R., Ho, Y.-C., Kelly, J.P., Robinson, S.M.: Integrating Optimisation and Simulation: Research and Practice. In: Proceedings of the 2000 Winter Simulation Conference, Arlington, VA, December 9-12. IEEE (2000)

13. Tempelmeier, H.: Practical considerations in the optimization of flow production systems. International Journal of Production Research 41(1), 149-170 (2003)

14. Chryssolouris, G., Chan, S., Cobb, W.: Decision Making on the Factory Floor: An Integrated Approach to Process Planning and Scheduling. Robotics and ComputerIntegrated Manufacturing 1(3/4), 315-319 (1984)

15. Chryssolouris, G.: Manufacturing Systems: Theory and Practice, 2nd edn. Springer, New York (2006)

16. Chryssolouris, G., Mavrikios, D., Papakostas, N., Mourtzis, D., Michalos, G., Georgoulias, K.: Digital manufacturing: history, perspectives, and outlook. Proceedings of the I MECH E Part B Journal of Engineering Manufacture 222, 451-462 (2008)

17. Chryssolouris, G., Papakostas, N., Mavrikios, D.: A perspective on manufacturing strategy: Produce more with less. CIRP Journal of Manufacturing Science and Technology 1, 45-52 (2008) 